\title{
Survival after cancer
}

\author{
Dr. C N Karunaratne MD, FRCA \\ Senior lecturer in Anaesthesiology, Department of Surgery, \\ General Sir John Kotelawala Defense University, Ratmalana,
}

On the $23^{\text {rd }}$ of August 2013, my life ended, well almost. I was diagnosed as a case of Stage II adenocarcinoma of the left lung.

Left lung was removed with hilar lymphnode clearance and horrendous monthly cycles of chemotherapy followed.

Here I am, almost two years after the most traumatic period of my/our lives.

To alarm you, let me give a brief account of "adenocarcinoma of the lung".

- Commoner in females

- Presents late in life

- No risk factors (apparent) i.e. Smoking, food etc.

- Survival after two years of treatment is $10-15 \%$

- Surgery followed by chemotherapy is the treatment of choice

Advancements in therapy

- More accurate in the diagnosis and staging

- Minimally invasive thoracotomy

- Advanced anaesthetic and pain relief Techniques

- Elaborate, guideline based enhanced recovery programmes post operatively.

- Use of more refined chemotherapeutic agents with regular updated monitoring of body biochemistry

- Focused rehabilitation

Publishing this in our journal is my way of praising our own health care professionals for providing the best possible care, in Sri Lanka.

The radiologists gave an accurate image of my lesions. The pathologists were able to stage my illness with pin point accuracy using immunoassays. The surgical team embarked on carrying out minimally invasive surgery using modern technology provided by the well equipped health care facility.

The anaesthesiologists provided the safest possible care, using modern drugs and devices. Pain relief was given paramount importance to make the recovery period uncomplicated and safe.

The oncology team undertook the protracted 6 month period of chemotherapy, via a skillfully placed central venous catheter.

My story has not ended yet. It is a combination of expert medical care, tender loving care provided by my family and friends, together with my determination to get back to a functioning life which has helped me to get on with life, so far.

The journey has not been easy for me, my family and friends. But we endure and face the adversities knowing that we are guided in our lives by the mysterious forces.

Since the illness, I have travelled to far corners of our beautiful island, made journeys to far away destinations, believing that I will be looked after.

Few tips of advice to whoever is faced with dilemmas of living.

- Never think that winning is impossible. Effort to live life to its fullest is our responsibility to ourselves, loved ones and whole of humanity.

- Never discourage anyone with negativity in life. Positive words, gestures go a long way. 
Karunaratne. Sri Lankan Journal of Anaesthesiology: 23(2):91-92(2015)

- Believe in guideline based new, refined medical therapy which is time tested and proven to cure illnesses.

- Everyone has a purpose in life, the commitment to self, family, friends and everyone else must go on irrespective of difficulties faced.
- Be grateful to what you have and not dwell on what unpleasantness has brought on.

- To fellow Sri Lankans - Believe in our health care system, provided by the world's best using modern evidence based practices. 